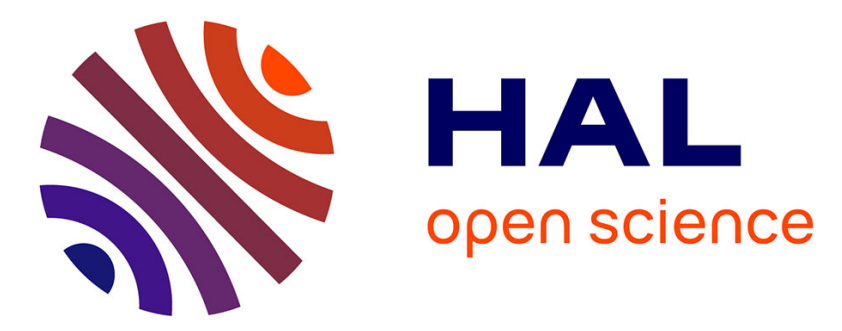

\title{
Photonic crystal mirror based optical microsources for silicon photonics
}

Xavier Letartre, Cédric Blanchard, Jean-Louis Leclercq, Christian Seassal, Pierre Viktorovitch

\section{- To cite this version:}

Xavier Letartre, Cédric Blanchard, Jean-Louis Leclercq, Christian Seassal, Pierre Viktorovitch. Photonic crystal mirror based optical microsources for silicon photonics. 7th International Photonics and OptoElectronics Meetings (POEM), Jun 2014, Wuhan, China. 10.1364/OEDI.2014.OF4A.7 . hal-01489810

\section{HAL Id: hal-01489810 https://hal.science/hal-01489810}

Submitted on 2 Jul 2021

HAL is a multi-disciplinary open access archive for the deposit and dissemination of scientific research documents, whether they are published or not. The documents may come from teaching and research institutions in France or abroad, or from public or private research centers.
L'archive ouverte pluridisciplinaire HAL, est destinée au dépôt et à la diffusion de documents scientifiques de niveau recherche, publiés ou non, émanant des établissements d'enseignement et de recherche français ou étrangers, des laboratoires publics ou privés. 


\title{
Photonic crystal mirror based optical microsources for silicon photonics
}

\author{
Xavier Letartre, Cédric Blanchard, Jean-Louis Leclercq, Christian Seassal, Pierre Viktorovitch \\ Université de Lyon, Institut des Nanotechnologies de Lyon (INL), UMR CNRS 5270, Ecole Centrale de Lyon, France \\ Xavier.letartre@ec-lyon.fr
}

\begin{abstract}
Surface-addressable photonic crystal membrane resonators are shown to constitute generic enablers for 3D harnessing of light. Conceptual approaches used to analyse their optical properties are briefly presented and leads to simple design rules. Application to VCSELS is emphasized.

OCIS codes: (230.0230) Optical devices; (230.6080) Sources (000.0000)
\end{abstract}

\section{Introduction}

High index contrast periodic structures can be exploited to perform an arbitrarily adjustable spatio-temporal molding of light at the wavelength scale. This tight control of photons is obtained through a shaping of resonant modes and a suitable adjustment of their coupling with propagative modes. In this talk, surface addressable (or above the light line) Bloch modes in photonic crystal membranes (PCMs) will be investigated. The concepts governing the properties of these modes will be first presented. It will be demonstrated that simple models can be considered to understand their behavior and, more specifically, their ability to capture photons during the desired lifetime. Bloch modes with a very large band width or a very high $\mathrm{Q}$ factor can be easily designed this way. Among the wide application range of these PCMs, we will focus on the exploitation of low Q Bloch modes, which act as broadband mirrors, to realize compact and efficient vertical cavity lasers with unprecedented functionalities

\section{Photonic Crystal Membrane with controllable bandwidth: a simple model}

A PCM is basically a membrane of high index $\left(\mathrm{n}_{\mathrm{H}}\right)$ dielectric embedded in a low index $\left(\mathrm{n}_{\mathrm{B}}\right)$ dielectric, and patterned to form a 1D or 2D grating with high index contrast (Figure 1, left). When operating above the light line, it behaves as a resonant reflector with $100 \%$ reflectivity at the resonant wavelength and with a bandwidth which can be adjusted through the geometric parameters of the PCM (thickness (h), duty cycle (DC), period $(\Lambda)$ ). It is illustrated on the right of Figure 1 where the reflectivity spectra of a 1D PCM are plotted as a function of the membrane thickness. It is shown that very narrow (close to zero) or very broad (up to 20\%) bandwidths can be reached.

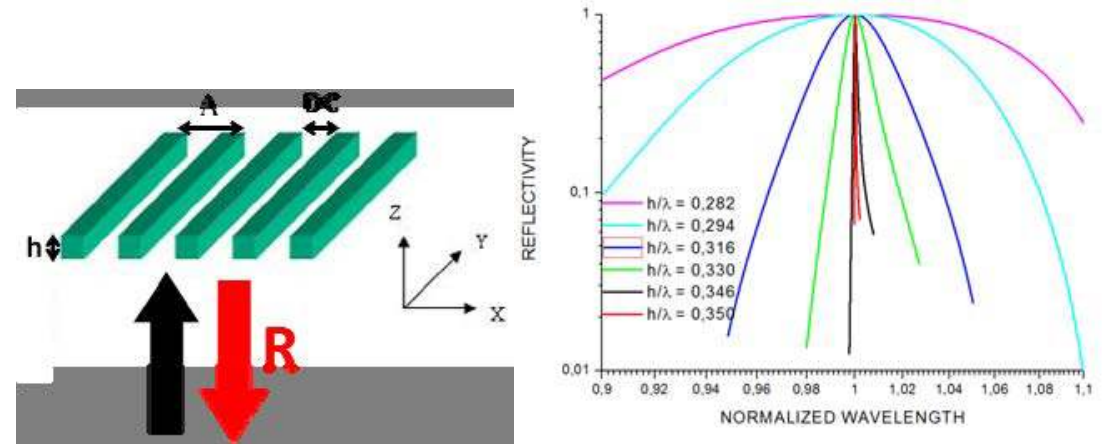

Figure 1: left: schematic view of a 1D PCM, right: reflectivity spectra, at normal incidence, of a 1D PCM as a function of the membrane thickness $(\mathrm{h})\left(\mathrm{n}_{\mathrm{H}}=3.481, \mathrm{n}_{\mathrm{L}}=1.528, \mathrm{DC}=50 \%, \Lambda\right.$ is modified for each spectrum in order to renormalized the resonant wavelength)

This plasticity allows for application in a wide range of optical devices. Narrow band PCMs (or high Q resonators) have been extensively used for surface addressable optoelectronic devices where an active material is embedded into the membrane, leading to the demonstration of low threshold surface emitting lasers ${ }^{1}$, nonlinear bistables ${ }^{2}$, optical traps ${ }^{3}$... A broadband $\mathrm{PCM}^{4,5}$ represents an ideal mirror to form compact vertical microcavity with 3D confinement of photons ${ }^{6}$ and polarization selectivity ${ }^{7}$. Among numerous devices, low threshold VCSELs with remarkable and tunable modal properties have been demonstrated in our group ${ }^{8,9}$ and at Berkeley University ${ }^{10}$. To summarize PCMs are resonant reflectors whose bandwidth (or Q factor) can be widely adjusted in order to match 
the requirements of a given application. It is therefore of prime importance to establish the physical rules which govern the lifetime of photons in these resonant modes.
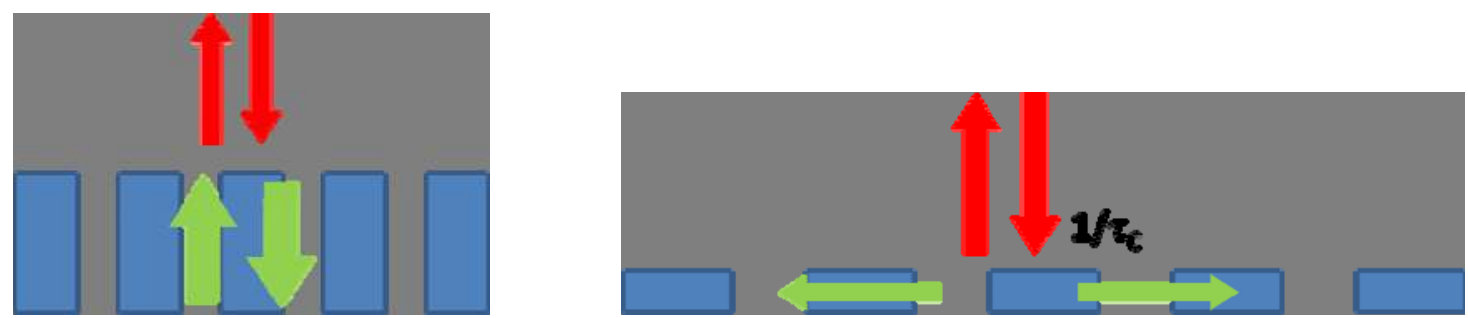

Figure 2: two approaches to understand the physics of PCMs: left: "Fabry-Perot" approach, right: "guided mode" approach

In the literature, two main models have been developed to address this point. In the first one ${ }^{11}$ the PCM is considered as a periodic array of waveguides carrying Bloch modes which propagate in the vertical direction (Figure 2, left). When impinging the bottom and top surfaces of the PCM, these modes can be transmitted, reflected or can couple to each others. Then the PCM acts, for each resulting hybrid modes, as a Fabry-Perot vertical cavity. It has been demonstrated in Ref.11 that the Q factor of the PCM modes is strongly determined by the interferences between these Fabry-Perot modes. In the second approach, which can be qualified as "orthogonal" to the previous one, the PCM is seen as a planar, periodically patterned, waveguide whose guided modes interact, through the corrugation, with the free space ones (Figure 2 right). In other words, the Bloch modes of the planar photonic crystal are first considered, disregarding their out of plane losses, even if they are located above the light line. In this last case, which is the only of interest in this study, the diffraction coupling to free space modes is characterized by a phenomenological parameter $1 / \tau_{\mathrm{C}}$, where $\tau_{\mathrm{C}}$ is the lifetime of photons before escaping out of the membrane. In this frame, the $\mathrm{Q}$ factor of the PCM (or the coupling rate $1 / \tau_{\mathrm{C}}$ ) is determined, to the first order, by the integral overlap between the electromagnetic field distributions of the guided and free space modes and of the dielectric periodic perturbation which is applied to the homogeneous membrane to get the photonic crystal. It turns out that the symmetries of these distributions are of prime importance for the strength of the resonance. The impact of the in plane symmetry of Bloch modes on their coupling strength with radiated modes had been recognized by J. M. Pottage and co-workers ${ }^{12}$ who reported on 2D PCM supporting wave-guided modes, resonantly coupled with radiated modes, with very high $\mathrm{Q}$ factors. The effect of the vertical symmetry has been less studied but is also significant. As an illustration, we have recently emphasized the fact that the strong dependence of the $Q$ factor with the PCM thickness can be understood by symmetry considerations ${ }^{13}$. This approach leads to an analytical formulation which allows for the simple design of PCMs with controllable bandwidth.

\section{PCM based VCSELS}

As discussed in the introduction, a low Q PCM is a mirror which leads to the design of planar microcavities where photons are confined in the vertical direction. However it will be demonstrated in this section that their specific properties allow for a 3D light trapping.

Recently, vertical-cavity surface-emitting lasers (VCSELs) emitting in C-band using a double set of onedimensional $\mathrm{Si} / \mathrm{SiO}_{2}$ photonic crystals as compact, flexible, and power efficient mirrors have been realized within a mass-scale fabrication paradigm by employing standard $200-\mathrm{mm}$ microelectronics pilot lines ${ }^{9,14}$. Conceived as the basic building block for photonics-on-silicon back-end integration of group III-V laser microsources, the extreme flexibility of the novel photonic architecture enables to perform a tailored modal selection of the optical cavity, including polarization and far-field control. It also offers a wide range of functionality, such as on-chip optical routing. Device compactness ensures a considerable reduction in the device footprint and power consumption. Furthermore, high fabrication yields obtained thanks to the state-of-the-art molecular wafer bonding of III-V alloys on silicon conjugate excellent device performances with cost-effective high-throughput production, indicating strong perspective industrial potential.

When two 1D PCMs are used to form a vertical cavity, as illustrated in Figure 3, the resulting resonant modes can be seen, in the "guided mode" approach, as hybrid modes with a waveguided component into the PCMs and a vertically radiated component in between the PCMs. Therefore, for a finite size microcavity, the confinement properties of the structure results not only from the reflectivity of the PCMs but also from the in-plane photons kinetics. This point can be exemplified through the design of the PCM-VCSEL depicted on Figure 3. This cavity aims at achieving laser emission at $2.3 \mu \mathrm{m}$ (TE polarized: electric field along $\mathrm{z}$ ) for application in mid infrared sensing. An antimony based active heterostructure is inserted between two broadband $\mathrm{Si} / \mathrm{SiO}_{2} \mathrm{PCM}$ mirrors and 
separated from the latter's by silica layers. Using FDTD simulations efficient 3D confinement will be demonstrated, confirming the hybrid nature of the resonant mode.

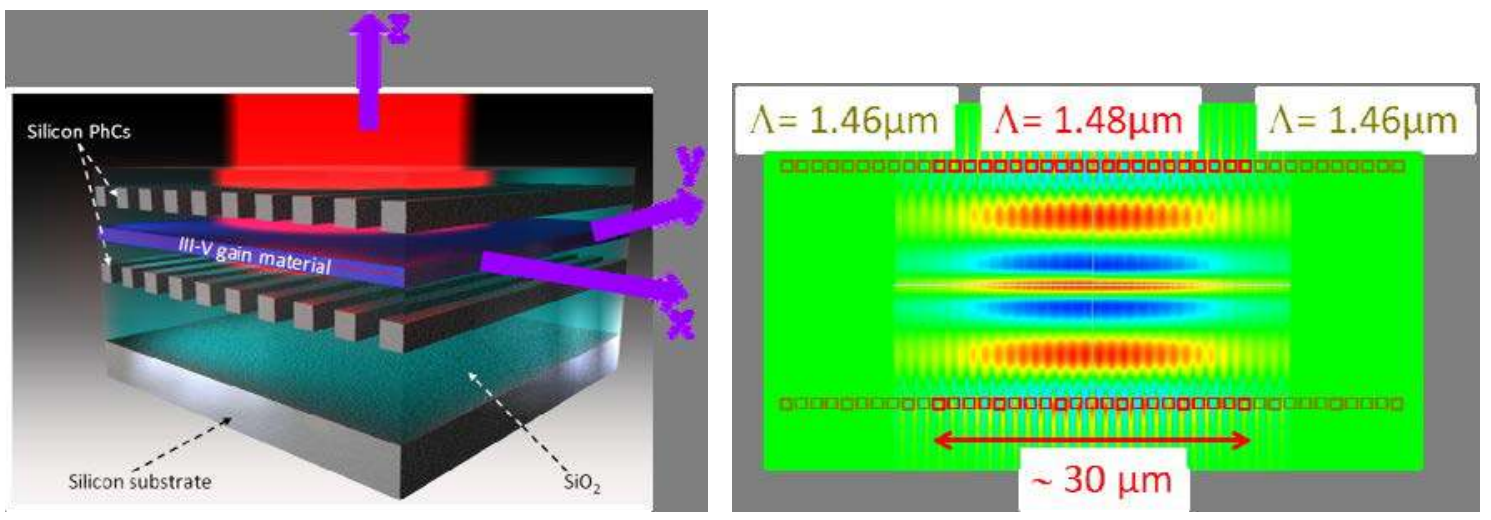

Figure 3: left: artistic representation of a PCMs based VCSEL, right: electric field distribution (y-cut) of the resonant mode and main parameters of the PCMs ( $\mathrm{DC}=48 \%$, the length of the bars constituting the $\mathrm{PCMS}$ is $\mathrm{L}_{\mathrm{Y}}=30 \mu \mathrm{m}$ )

\section{Conclusion}

In the present communication, surface-addressable photonic crystal membrane resonators are shown to constitute generic enablers for 3D harnessing of light. Conceptual approaches used to analyse their optical properties are briefly presented and natural routes leading to simple design rules of those structures are given. The application of PCMs to a wide range of devices is described, showing the versatility of these simple periodic structures.

\section{Acknowledgement}

The research leading to these results has received funding from the French National Research Agency (ANR projects MOREMIR and IDEE).

\section{References}

[1] J. Mouette, C. Seassal, X. Letartre, P. Rojo-Romeo, J.-L. Leclercq, P. Regreny, P. Viktorovitch, E. Jalaguier, P. Perreau, H. Moriceau, "Low threshold, room temperature vertical emitting laser based on an InP two-dimensional photonic crystal," Electron. Lett. 39, 526 (2003).

[2] C. Cojocaru, F. Raineri, P. Monnier, C. Seassal, X. Letartre, P. Viktorovitch, A. Levenson, R. Raj, "Ultrafast dynamics of the thirdorder nonlinear response in a two-dimensional InP-based photonic crystal,” Appl. Phys. Lett. 85, 1880 (2004)

[3] Benyattou, T., Gerelli, E. ; Milord, L. ; Jamois, C. ; Harouri, A. ; Chevalier, C. ; Seassal, C. ; Belarouci, A. ; Letartre, X. ; Viktorovitch, P., "Slow bloch mode cavity for optical trapping", 15th International Conference on Transparent Optical Networks (ICTON), June 23-27 (2013), Cartagena (Spain)

[4] H. T. Hattori, X. Letartre, C. Seassal, P. Rojo-Romeo, J.- L. Leclercq, and P. Viktorovitch, "Analysis of hybrid photonic crystal vertical cavity surface emitting lasers" Opt. Express 11, 1799 (2003).

[5] C. F. R. Mateus, M. C. Y. Huang, Y. Deng, A. R. Neureuther, and C. J. Chang-Hasnain, "Ultra-broadband mirror using low index cladded subwavelength grating," IEEE Photon. Technol. Lett. 16, 518-520 (2004).

[6] P. Viktorovitch, B. Ben Bakir, S. Boutami, J.-L. Leclercq, X. Letartre, P. Rojo-Romeo, C. Seassal, M. Zussy, L. Di Cioccio, and J.-M. Fedeli, "3D harnessing of light with 2.5D photonic crystals," Laser \& Photon. Rev. 4, 401-413 (2010).

[7] S. Boutami, B. B. Bakir, H. Hattori, X. Letartre, J.-L. Leclercq, P. Rojo-Romeo, M. Garrigues, C. Seassal, and P. Viktorovitch, "Broadband and compact 2-D photonic crystal reflectors with controllable polarization dependence," IEEE Photon. Technol. Lett. 18, 835-838 (2006).

[8] S. Boutami, B. Ben Bakir, J.-L. Leclercq, and P. Viktorovitch, "Compact 1.55- $\mu \mathrm{m}$ room-temperature optically pumped VCSEL using photonic crystal mirror," Electron. Lett. 43, 282-283 (2007).

[9] C. Sciancalepore, B. Ben Bakir, X.Letartre, J. Harduin, N. Olivier, C. Seassal, J.-M. Fedeli, and P.Viktorovitch, "CMOS-compatible ultra-compact 1.55- $\mu \mathrm{m}$ emitting VCSELs using double photonic crystal mirrors," IEEE Photon. Technol. Lett. 24, 455-457 (2012).

[10] M. C. Y. Huang, Y. Zhou, and C. J. Chang-Hasnain, "A surface-emitting laser incorporating a high-index-contrast subwavelength grating," Nat. Photonics 1, 119-122 (2007).

[11] V. Karagodsky and C. J. Chang-Hasnain, "Physics of near wavelength high contrast gratings," Opt. Express 20, 10888-10895, (2012)

[12] J. M. Pottage, E. Silvestre and P. St. J. Russel, "Vertical-cavity surface-emitting resonances in photonic crystal films", J. Opt. Soc. Am. A 18, 442-447 (2001)

[13] Xavier Letartre, Pierre Viktorovitch, Corrado Sciancalepore, Taha Benyattou, Badhise Ben Bakir, "Surface addressable Photonic Crystal resonators: general design rules and applications", 14th International Conference on Transparent Optical Networks (ICTON), July 2-5 (2012), Coventry (England)

[14] C. Sciancalepore, B. Ben Bakir, S. Menezo, X.Letartre, D. Bordel, and P.Viktorovitch, "III-V-on-Si Photonic Crystal Vertical-Cavity Surface-Emitting Laser Arrays for Wavelength Division Multiplexing,” IEEE Photon. Technol. Lett. 25, 1111-1113 (2013). 